\title{
Eau de vie
}

\section{How water shaped our planet and serves as the essence of life on Earth.}

\author{
Water from Heaven: The Story of \\ Water from the Big Bang to the \\ Rise of Civilization, and Beyond \\ by Robert Kandel \\ Columbia University Press: 2003. 312 pp. \\ $\$ 27.95, £ 20$
}

\section{Daniel Hillel}

Life on Earth began in an aquatic medium, and water is still the principal constituent of all living organisms. In the words of Russian scientist Vladimir Vernadsky, written more than a century ago: "Life is animated water."

Robert Kandel's new book is an attempt to lay out the entire epic story of water from the beginning of the Universe to the present, and even on to the future, all in the space of 300 or so dense pages. As such, it is an audacious tour de force that sweeps across time and space at a breathtaking pace. Given the enormous scale and ambition of the undertaking, it is perhaps not surprising that the quality of the coverage is somewhat uneven.

The first two parts - "Water in the Universe from the Big Bang to the Appearance of Man" and "Water in Today's World" are the most captivating, and demonstrate the author 's mastery of such diverse fields as cosmology, astrophysics, geophysics, geochemistry, hydrology, oceanography and climatology. Complex scientific concepts and interrelationships are presented systematically in language that is understandable to the educated lay reader. Kandel displays impressive didactic powers in making intricate concepts clear without resorting to jargon or mathematical equations.

Particularly informative are the explanations of planetary motion (including such phenomena as Earth's spin and obliquity), the Milankovitch cycle, the recurrent ice ages, cloud formations and precipitation, the inter-tropical convergence zone, the El Niño and La Niña oscillations, as well as the natural and the enhanced greenhouse effect. Kandel also sheds light on the interplay between the inherent regularity of the Earth's processes and the mechanisms that cause deviations from that regularity.

Reading and pondering all that leaves one marvelling at the extremely improbable and fortuitous circumstances (including the exact distance from the Sun and the precise values of gravity and ranges of pressure and temperature) that allow water on the surface of our planet to exist in all three interchangeable phases and to make life possible. The discourse is reinforced with a few (one would have wished for more) schematic illustrations.

Among Kandel's insights is an explanation

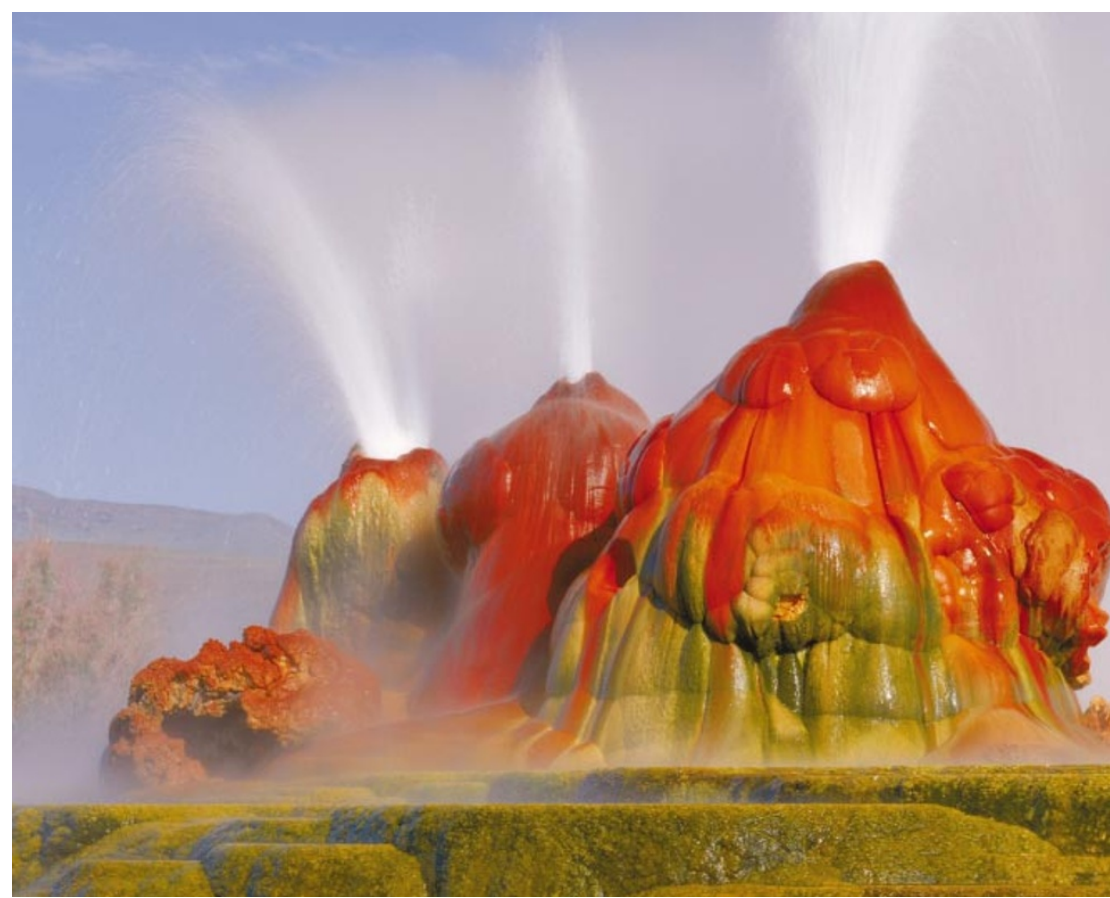

A splash of colour: jets of hot water spurt out from geysers in Nevada's Black Rock Desert.

of how photosynthesis by aquatic plants enriched the atmosphere with oxygen, which led eventually to the formation of the stratospheric ozone layer. This in turn provided the shield against ultraviolet radiation that allowed life to move onto dry land. He also includes notes about some of the pioneers of the Earth sciences and how the science evolved.

The narrative deteriorates somewhat in the third part of the book, which deviates from strict science into controversial issues relating to the role of water in human history and contemporary affairs. Kandel is right to point out that in many countries (particularly in the arid zone), "agriculture is the biggest water user", and that saving water depends on the "more efficient use of water in agriculture". But he makes no distinction between the processes of evaporation from the soil (which is a loss) and transpiration by plants (a climatically imposed necessity linked to plant productivity), and the concurrent processes of percolation and runoff. The blanket statement that "most of the water used by agriculture returns to the atmosphere by evapotranspiration" is not necessarily true in irrigated agriculture. Where irrigation is inefficient, much of the applied water runs off or percolates through the root zone, raising the water table and causing waterlogging and salination. Only in highly efficient irrigation is nearly all of the water applied transpired by the crops.

Various other errors are made, too. One is the statement that 500 cubic metres of water per person per year is "an absolute vital minimum", whereas Israel, for example, uses little more than 300 (including water for irrigation) and Jordan even less than that. And it is not only Egypt that "makes intensive use of Nile water"; Sudan uses up to 18.5 billion cubic metres of Nile water per year (one-third of Egypt's usable share of 55.5 billion cubic metres).

More regrettable are the author's digressions into the realm of polemics and his penchant for authoritative expressions of negative opinions regarding "ecologists" (the quotation marks are the author's), who, he thinks, make "completely wrong assertions" that are far too current among environmental movements. He repeats the castigations of "self-styled ecologists" later in the book without specifying exactly to whom and to what they refer. More explicit is his opinion that it is "grotesque" that the US government, "hijacked in 2000-2001 by the oil and coal industries, should maintain that the high-tech US economy depends on wasting crude oil and coal". Such political pronouncements are unbecoming in a science book, which ought to be more objective.

The writing is generally lively and accessible, although the discussion often rambles, with frequent meanderings and non sequiturs. 
Such minor shortcomings notwithstanding, the book is for the most part a masterful treatment of a complex subject that is of vital and growing importance. All in all, it is a worthy contribution to the popular literature on environmental topics. It teaches much about the primary substance of life and about our utter dependence on it. I recommend the book highly, and the first two sections of it unreservedly.

Daniel Hillel is professor emeritus of soil physics and hydrology, University of Massachusetts, and is currently senior visiting fellow at the Center for Climate Systems Research, Columbia University, Goddard Institute for Space Studies, 2880

Broadway, New York, New York 10025, USA.

\section{The last word on books?}

\section{A History of Reading}

by Steven Roger Fischer

Reaktion: 2003. 384 pp. \$29.95, £19.95

\section{Maurice Pope}

Starting from the Bronze Age and ending with modern e-mails and a possible future of e-books, Steven Fischer's A History of Reading takes in a wonderful diversity of things. There is a letter to the king of the Hittites from Tutankhamun's widow asking him to let her marry one of his sons; some tenthcentury Japanese ladies' literature; reading in the lavatory in twelfth-century Europe; ancient Chinese book-burning; Dr Johnson's advice on what to read and how; Noah Webster's establishment of a patriotically independent American orthography (at a time when for a black man in the South to learn how to read was a crime punishable by flogging or mutilation); statistics on book production; and a discussion of issues such as dyslexia.

But the book is far from being a fact-filled encyclopaedia. It has enthusiasm, opinions (for instance, about how to teach reading and about the problems posed by today's increased accessibility of knowledge), and courage (in declaring that fundamentalism, whether Christian or Muslim, is a threat to civilization, and attacking it accordingly).

It also has direction. "No God revealed everything to us in the beginning," said the Greek poet Xenophanes in the sixth century BC, "but people make discoveries and improvements over time." This was the leitmotiv of Fischer's book on writing, and, perhaps more surprisingly, it also applies to this one on reading. There has been constant progress, not only in the methods of production but in the ease of consumption. Clay, papyrus, parchment, paper and electronic screen represent a ladder of improvement in convenience and cost. So does the change

\section{Philology \\ The pages of history}

The knowledge of the ancient Greeks found an indirect route to modern European scholars. Works written on parchment or papyrus were serially copied, often unfaithfully, by scribes and translators, as the originals fell apart.

So a copy of Ptolemy's Geographia in the original Greek, dating from as early as AD 1300 , which has recently come to light in the Topkapi Palace Museum in Istanbul, is causing a stir among philologists. The 120 parchment pages of text and maps, in an admittedly poor state of

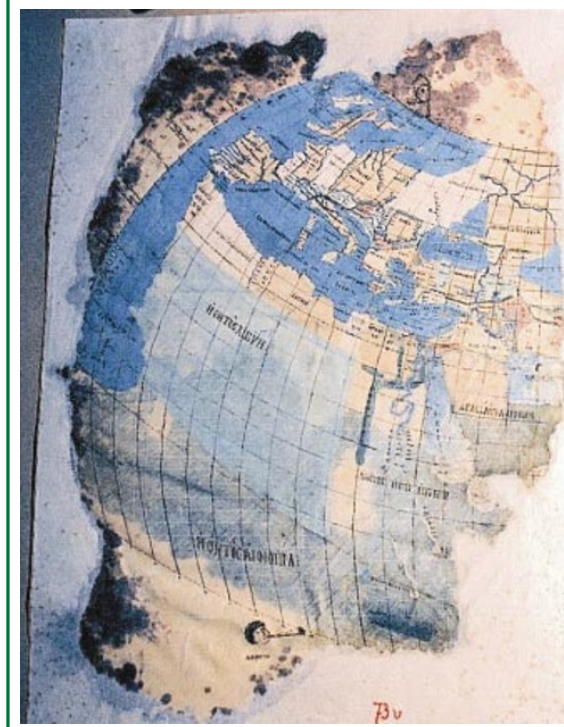

repair, are now being examined and annotated by a team at the University of Bern, Switzerland. The team, led by philologist Florian Mittenhuber, is preparing to publish the volume in its entirety, with a German translation.

Differences have already been observed between this Greek text and that of the first Latin translation of Geographia from AD 1406, which became the standard in Renaissance Europe and accompanied Christopher Columbus on his voyages to the New World.

\section{Alison Abbott}

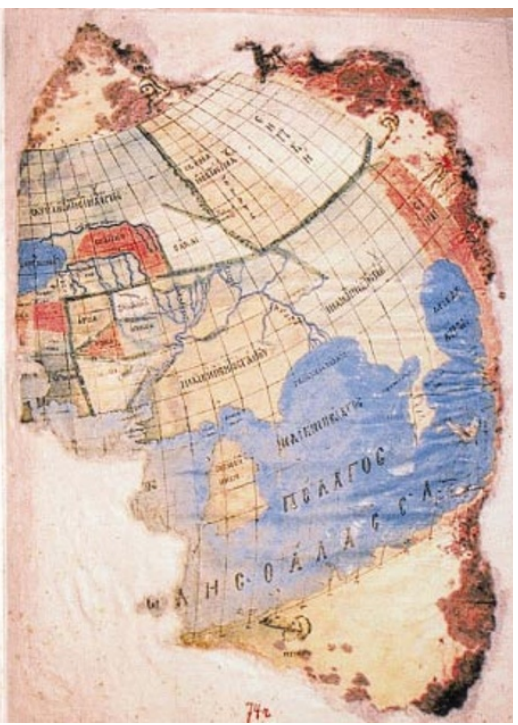

Old world? This version of Ptolemy's Geographia in the original Greek dates from about AD 1300.

from waxed tablet to notepad, and from scroll to book.

There has also been, in our own culture at least, an enormous improvement in presentation. In the Greco-Roman world a scroll (volumen) was much shorter than the average modern book, and a single work might need many volumes. Checking an earlier chapter did not mean just flipping back the pages but a tedious re-winding. There was no table of contents and no index. Worst of all, from our point of view, the text ran solidly without break. There was no punctuation except for a space and a brief line in the margin at the start of a new paragraph. There were not even gaps between words. All of these aids to the reader were introduced, gradually and unmethodically, over a span of some 2,000 years. Furthermore, there was no electric light and there were no reading glasses. For us today, each of these deficiencies would represent a major hurdle, and when we consider them all together we can be amazed at the high literacy rate among our ancestors.

Fischer also sees progress within our own brains. If it is true that all reading was vocalized until about 1,500 years ago, it may be that the advent of silent reading not only made the process faster but changed its nature. If so, we may be witnessing a new mental faculty in process of evolution.

This theory was first put forward by Julius Jaynes in 1976, and seems somewhat sensational. But adventurous ideas can be forgiven; wrong statements cannot. Fischer says that the Phaistos Disk "apparently conveys a mobilisation proclamation in Minoan Greek". But there is no such language known to scholarship, nor is the decipherment accepted. And the Roman poet Horace did not "boast that his Ars Poetica was selling along the Bosporus, in Spain, Gaul, and Africa" - this would have been extraordinary because the Ars Poetica is an essay on literary criticism. What Horace claimed was that his poetry was world-famous. The mistake may be trivial but it could not have been made by anyone who was writing from first-hand knowledge or who verified his references.

Indeed, Fischer relies heavily on secondary sources, more often than not without acknowledging it. If, to take a random sample, 